\title{
Neutralizing anti-4-1BBL treatment improves cardiac function in viral myocarditis
}

\author{
Caroline TY Cheung ${ }^{1}$, Theresa A Deisher², Honglin Luo1, Bobby Yanagawa', Stefanie Bonigut ${ }^{2}$, Amrit Samra ${ }^{1}$, \\ Hongyan Zhao ${ }^{1}$, Elizabeth $\mathrm{K}$ Walker $^{1}$ and Bruce M McManus ${ }^{1}$
}

Coxsackievirus B3 (CVB3) is the most common causative agent of infectious myocarditis. Chronic inflammation, loss of contractile tissue, and maladaptive remodeling all contribute to dilated cardiomyopathy and heart failure. The 4-1BB receptor is a costimulatory molecule expressed by T cells and cardiomyocytes. We infected mice with CVB3 to examine if virus infection triggers 4-1BB activation and whether inhibition of this pathway will reduce inflammation and improve heart function. Echocardiography was performed on days 3, 9, 30 and at 10 weeks post-infection (pi) and ejection fraction (EF), left ventricular (LV) wall thickness, contractility, and internal cardiac dimensions were measured. At day 9, reduced rate of wall thickening $(30 \pm 17$ vs $70 \pm 19 \%)$, increased LV wall thickness $(0.15 \pm 0.04$ vs $0.09 \pm 0.01 \mathrm{~cm}$ in diastole and $0.19 \pm 0.04$ vs $0.15 \pm 0.02 \mathrm{~cm}$ in systole), and reduced cardiac volume $(0.013 \pm 0.004$ vs $0.023 \pm 0.003 \mathrm{ml}$ in diastole and $0.004 \pm 0.002 \mathrm{ml}$ vs $0.007 \pm 0.001 \mathrm{ml}$ in systole) were observed in infected hearts as compared with shams. At 14 days pi, CVB3-infected mice were randomly assigned to receive either anti-4-1BBL neutralizing (M522) or control antibodies (Ab) for 8 weeks. Cardiac damage, fibrosis, and inflammation were assessed by histological stains and immunohistochemistry. Polymerase chain reaction (PCR) was utilized to detect matrix metalloproteinase (MMP)-2, MMP-9, and MMP-12 expressions. At 10 weeks pi, M522 treatment improved LV wall thickening rate $(-10 \pm 13$ vs $-49 \pm 16 \%$, expressed as percentage change from baseline) and reduced diastolic LV posterior wall thickness (17 \pm 10 vs $57 \pm 47 \%$, expressed as percentage change from baseline), cardiac damage as assessed by histological scores ( 0 vs $1.3 \pm 1.5$ ), fibrosis by collagen volume fraction ( $3.2 \pm 0.6$ vs $4.9 \pm 2.2 \%)$, overall inflammation $(5.9 \pm 1.3$ vs $8.5 \pm 4.1 \%)$, and T-cell infiltration $(1.3 \pm 0.9$ vs $4.3 \pm 3.8 \%)$ as compared to control. MMP- 12 was highly increased during acute and chronic myocarditis, but was significantly decreased by M522 treatment. Thus, long-term inhibition of the 4-1BB pathway reduces cardiac damage, remodeling, and inflammation during viral myocarditis.

Laboratory Investigation (2007) 87, 651-661; doi:10.1038/labinvest.3700563; published online 30 April 2007

KEYWORDS: 4-1BB; antibody treatment; CVB3; echocardiography

Coxsackievirus B3 (CVB3), a member of the Picornaviridae family, is the leading cause of viral myocarditis, of which dilated cardiomyopathy (DCM) is a major sequela. ${ }^{1}$ Both direct viral and immune-mediated mechanisms have been shown to contribute to the pathogenesis of acute injury and subsequent cardiac remodeling. ${ }^{2,3}$ Murine myocarditis may be conceptualized in three phases: (1) viremia up to day 3 post-infection (pi); (2) inflammation from day 5 to day 14 pi; and (3) reparation and remodeling after 14 days pi. ${ }^{4}$ Major determinants of long-term heart failure are the degree of cardiac tissue loss by apoptotic or necrotic mechanisms and cardiac remodeling following these damages. Virus-induced myocytolysis occurs early in the infective period and despite viral clearance, ongoing inflammation may still occur, thus aggravating the disease by influencing cardiac restructuring and cell death events.

$\mathrm{T}$ lymphocytes have frequently been found in chronic myocarditis cases, thus implicating a pathogenic role. Previous studies have shown contrasting results in CVB3infected $\mathrm{T}$ cell-deficient mice. Coxsackievirus infection of severe combined immunodeficient (SCID) mice, which lack all lymphocytes, resulted in severe acute myocarditis due to uncontrolled viral replication and increased myocytolysis. ${ }^{5}$ However, viral infection in nude mice, which lack all $\mathrm{T}$ cells,

\footnotetext{
'Department of Pathology and Laboratory Medicine, The James Hogg iCAPTURE Centre for Cardiovascular and Pulmonary Research, St Paul's Hospital/Providence Health Care, University of British Columbia, Vancouver, BC, Canada and ${ }^{2}$ Department of Inflammation, Amgen, Inc., Seattle, WA, USA

Correspondence: Dr BM McManus, MD, PhD, Department of Pathology and Laboratory Medicine, The James Hogg iCAPTURE Centre for Cardiovascular and Pulmonary Research, St Paul's Hospital/Providence Health Care, University of British Columbia, Room 166-1081 Burrard Street, Vancouver, BC, Canada V6Z 176.

E-mail: bmcmanus@mrl.ubc.ca

Received 5 February 2007; revised 20 March 2007; accepted 29 March 2007
} 
as well as CD4/CD8 double knockout mice and $\alpha / \beta \mathrm{T}$ cell receptor (TCR)-deficient animals developed less inflammation and cardiac injury during the chronic phase of the disease. $^{6-8}$ These latter studies suggest that $\mathrm{T}$ cells may be detrimental in the pathogenesis of myocarditis, particularly during the chronic phase of the disease.

The 4-1BB pathway belongs to the tumor necrosis factor receptor (TNFR) family and consists of the receptor 4-1BB and its ligand 4-1BBL. It has been studied extensively in the immune system where they were first discovered as costimulatory molecules involved in T cell activation. ${ }^{9}$ The $4-1 \mathrm{BB}$ antigen is a cell membrane protein, which is usually induced on activated $\mathrm{T}$ cells and acts to influence effector functions and $\mathrm{T}$ cell numbers in the late stage of the acquired immune response. ${ }^{10}$ The most well-characterized ligand for this receptor is $4-1 \mathrm{BBL}$, which is constitutively expressed on plasma monocytes and dendritic cells, but can also be induced on $\mathrm{B}$ cells, activated macrophages, as well as cardiomyocytes. ${ }^{11,12}$ Stimulation of 4-1BBL expression can occur by CD40/CD40L ligation, LPS, and other toxic and infectious insults. ${ }^{13}$ Upon activation, 4-1BB-expressing cells upregulate the secretion of cytokines, such as interleukin (IL)-6, IL-8, and TNF- $\alpha{ }^{13,14}$ The 4-1BB signaling pathway plays crucial roles in the enhancement of integrin-mediated cell adhesion, regulation of $\mathrm{T}$ cell effector functions, and prevention and/or stimulation of cell death of leukocytes. ${ }^{15-17}$ In contrast to its role as a survival factor for activated CD8 $+\mathrm{T}$ cells, $4-1 \mathrm{BB}$ has also been implicated in activation-induced cell death in $\mathrm{CD} 4+\mathrm{T}$ cells as well as stimulation of apoptosis in neutrophils and B cells. ${ }^{12,18,19}$ Previously, initiation of cell death through the CD95 (Fas, APO-1) pathway and subsequent activation of effector caspases had been suggested, but recent studies have shown involvement of alternate mechanisms. ${ }^{12,20}$

Recently, the importance of these costimulatory molecules has been shown in the pathogenesis of myocarditis and in heart failure. Both $4-1 \mathrm{BB}$ receptor and its ligand are upregulated in cardiomyocytes during CVB3 infection as well as cardiotoxic and ischemic conditions in both murine models and patients (unpublished data). ${ }^{21-23} \mathrm{~A}$ study by Seko et $\mathrm{al}^{22}$ reported that inhibition of the 4-1BB pathway significantly attenuated inflammation and myocardial injury during the acute phase of myocarditis in mice but the functional consequences are yet unknown. Our research has demonstrated that blockade of the 4-1BB pathway improves cardiac function in a cytotoxic model using doxorubicin and in acute myocardial infarction (MI). Furthermore, agonism of the 4-1BB receptor exacerbates cytotoxic cardiac damage. In vitro studies demonstrated that 4-1BB can be expressed on injured cardiomyocytes and induces apoptosis via mitochondrial disruption.

In this study, we demonstrate the effect of inhibition of the $4-1 \mathrm{BB}$ receptor on cardiac function during the chronic phase of myocarditis by treating CVB3-infected mice with a neutralizing monoclonal anti-4-1BBL antibody $(\mathrm{Ab})$.

\section{MATERIALS AND METHODS}

\section{Virus Infection and Animal Treatment}

Viral stocks were propagated by passaging through HeLa cells and titers were routinely determined by standard plaque assay procedure. ${ }^{24}$ A pilot study was performed to determine the course of cardiac changes after CVB3 infection. For this study, five-week-old male A/J mice (Jackson Laboratories, Bar Harbor, MN, USA) were infected with cardiovirulent CVB3 (Gauntt strain, $10^{5}$ plaque-forming units (PFU)) or sham-infected with phosphate-buffered saline (PBS) and four mice were killed per day at 3,9 , and 30 days pi. In our chronic study, five-week-old adolescent male A/J mice were infected with CVB3 or sham-infected with PBS and at 14 days pi, mice were assigned to the following treatment groups: (1) CVB3 and neutralizing anti-4-1BBL Ab (M522) $(n=9)$; (2) CVB3 and nonblocking anti-4-1BBL Ab (M525, control) $(n=10)$; (3) sham and neutralizing M522 $(n=12)$; and (4) sham and nonblocking control $\mathrm{Ab}(n=12)$. Treatments began on day $15 \mathrm{pi}$, following resolution of the inflammatory phase, by weekly intraperitoneal injections of $250 \mu \mathrm{g}$ neutralizing M522 or nonblocking control Ab. Antibodies were produced in rats and affinity purified for rat IgG2a isotypes (Amgen Inc., Thousand Oaks, CA, USA). All surviving mice were killed at 10 weeks pi. This investigation conforms to the Guide for the Care and Use of Laboratory Animals published by the US National Institutes of Health (NIH Publication No. 85-23, revised 1996) and the Animal Care Committee, University of British Columbia.

\section{Fluorescent Immunohistochemistry}

Mid-ventricular cardiac tissue as well as kidney, thymus, pancreas, and spleen were fixed in $10 \%$ formalin and embedded in paraffin. Serial sections of mid-ventricular heart tissue were deparaffinized in subsequent washes of xylene and alcohol, and blocked with universal protein block (Dako, Mississauga, ON, Canada). The slides were then treated with $0.2 \mathrm{M}$ glycine for $20 \mathrm{~min}$ at room temperature. For fluorescent detection of $4-1 \mathrm{BB}$, we used $1 \mu \mathrm{g} / \mathrm{ml}$ of $4-1 \mathrm{BBL}$ antigen fused to a leucine zipper (LZ) motif (Amgen) followed by Alexa Fluor ${ }^{\circledR}$ 488-labeled anti-LZ Ab. For detection of $4-1 \mathrm{BBL}, 1 \mu \mathrm{g} / \mathrm{ml}$ of human Fc-linked $4-1 \mathrm{BB}$ antigen was applied followed by Alexa Fluor ${ }^{\circledR}$ 594-labeled antihuman immunoglobulin (Molecular Probes/Invitrogen, Carlsbad, CA, USA) secondary Ab. Stained sections were viewed using the Leica SP2AOBS confocal laser scanner on a Leica DM IRE inverted microscope. At least 10 images were photodocumented from each mouse sample using $\times 20$ objective lens and morphometric analyses were performed to calculate the percentage of immunoreactivity within each image, which were then averaged to obtain the total percentage of staining for each individual sample.

\section{Echocardiography}

Mice were anesthetized with $100 \mathrm{mg} / \mathrm{kg}$ ketamine and $7.5 \mathrm{mg} / \mathrm{kg}$ xylazine, and echocardiograms were recorded using the SONOS 
5500 (Philips Medical, Bothell, WA, USA) ultrasound machine and a pediatric phased array probe at a frequency of $12 \mathrm{MHz}$. For the pilot study, echocardiography was performed at days $0,3,9$, and 30 pi. For treatment groups in the chronic study, echocardiography was performed on day 9 and then weekly from 3 to 10 weeks pi. Mice were placed prone on a $1 \mathrm{~cm}$ thick agarose gel pad on a temperature-controlled modified microscope stage. Views were standardized serially and between mice with strict adherence to the anatomical guidelines and conventions established by the American Society of Echocardiography. ${ }^{25}$ Echocardiographic images were taken from 2D M-mode, parasternal long axis views, and short axis views at the mitral valve and mid-papillary muscle levels. Measurements were taken at both diastole and systole, and included: left ventricular (LV) internal cardiac dimensions, $\mathrm{LV}$ area at the level of the mitral valve, $\mathrm{LV}$ area at the level of the papillary muscles, and posterior wall (PW) thickness. Cardiac output, stroke volume, ventricular volume, and ejection fraction (EF) were calculated utilizing the Modified Simpson's algorithm using both M-mode and B-mode measurements for increased accuracy.

\section{Histological Examination}

Mid-ventricular heart tissue was deparaffinized, sectioned to $4 \mu \mathrm{m}$, and processed for hematoxylin and eosin (H\&E) staining, to detect myocardial injury and inflammatory infiltration, and picrosirius red staining for collagen amount and orientation. Stained sections were viewed using light microscopy and graded in a blinded manner by a pathologist (BMM) based on the following scale: 0 , no or questionable presence of immune cells and/or necrosis; 1 , limited focal distribution; $2-3$, intermediate severity; and 4-5, coalescent and extensive lesions over the entirety of the transversely sectioned ventricular tissue. H\&E sections were graded based on the degree of myocardial necrosis, inflammation, and scar formation within tissue sections. At least 10 images were photodocumented and analyzed from each sample at $\times 20$ magnification.

\section{Reverse Transcriptase-Polymerase Chain Reaction (RT-PCR)}

The basal and apical cardiac sections were flash-frozen and homogenized for nucleic acid extraction. RT-PCR was used to detect the transcript levels of matrix metalloproteinase (MMP)-2, -9, and -12 after virus infection and 4-1BBL Ab treatment. Total mouse RNA was isolated using the RNeasy kit (Qiagen, Valencia, CA, USA) and $0.5 \mu \mathrm{g}$ of RNA was converted to cDNA using the Superscript reverse transcriptase II kit (Invitrogen, Carlsbad, CA, USA) according to the manufacturer's protocol. The PCR primers and conditions are described elsewhere. ${ }^{26}$ For normalization, $18 \mathrm{~S}$ was used as control.

\section{Immunohistochemistry}

For detection of the pan-leukocyte marker CD45 and panT-cell marker CD3, epitopes were uncovered by heating tissue sections in $0.1 \mathrm{M}$ citrate buffer, $\mathrm{pH} 6.0$, followed by overnight incubation in $20 \mu \mathrm{g} / \mathrm{ml}$ of anti-CD45 Ab (BD Biosciences, Mississauga, ON, Canada) or anti-CD3 Ab (Dako). The ABComplex amplification system (Dako) in conjunction with 3,3'-diaminobenzidine (DAB), a horse radish peroxidase substrate, was used for detection of immunopositivity. Images were captured using a Nikon E600 inverted microscope and Spot digital camera. A minimum of 10 images were photodocumented and analyzed from each sample at $\times 20$ magnification.

\section{Statistical Analyses}

Morphometric analyses, using the Image-Pro Plus ${ }^{\mathbb{R}}$ software (Media Cybernetics, Silver Spring, MD, USA), were performed to calculate the percentage of picrosirius red staining as well as CD45 and CD3 immunoreactivity. Picrosirius red staining was calculated as the average percentage of red (collagen) as compared to yellow staining (muscle) within at least 10 photodocumented images. Immunoreactivity for CD45 and CD3 was calculated as the average percentage of positively stained cells as compared to the total number of cells within each given image. Data are expressed as mean \pm s.d. in all texts and graphs. Pairwise comparisons between M522 and control samples were conducted using two-tailed, unpaired Student's $t$-test or Mann-Whitney $U$-test, and multiple comparisons were analyzed using analysis of variance and Tukey's post-test, where $P<0.05$ is indicative of statistical significance.

\section{RESULTS}

Immunohistochemical Staining for 4-1BB and 4-1BBL

Seko $e a^{22}$ reported an induction of 4-1BBL expression in cardiomyocytes following CVB3 infection. Our previous observations have shown that $4-1 \mathrm{BB}$ and $4-1 \mathrm{BBL}$ can be induced in cardiomyocytes after various stimuli, such as doxorubicin treatment and MI in mice (unpublished data). Therefore, we examined the presence and amount of these two proteins in sham and CVB3-infected hearts at 9 days pi. Figure 1a demonstrates minimal expression of the 4-1BB receptor (green, top small panel) in sham mouse hearts and strong expression of 4-1BBL (red, lower small panel), whereas at 9 days pi (Figure 1b), there was increased expression of $4-1 \mathrm{BB}(39 \pm 14$ vs $0 \%, P<0.01)$, which colocalized with cardiomyocytes (long arrow), in infected hearts as compared to sham. The expression of $4-1 \mathrm{BBL}$ remained constant throughout the infection. The receptor and ligand colocalized predominantly in cardiomyocytes (Figure $1 \mathrm{~b}$, yellow, long arrow) but were also expressed by small round cells, possibly immune cells (small arrow). Figure if shows the graphical representation of the densitometric analyses.

For the chronic study, to confirm target coverage of the anti-4-1BBL antibodies (M522 and control Abs) into the mouse hearts, immunostaining for rat IgG2a was performed and immunopositivity was observed in all samples (data not shown). Immunofluorescent staining for 4-1BB and 4-1BBL 
a
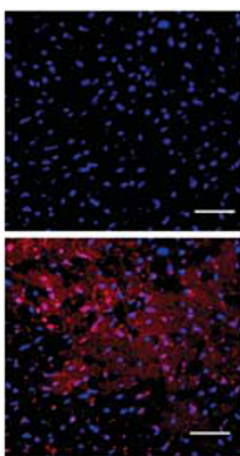

C

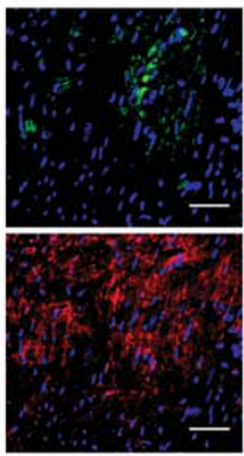

e

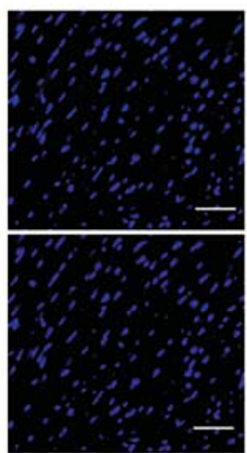

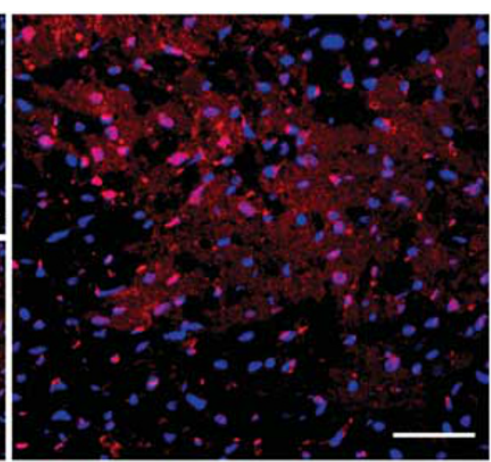
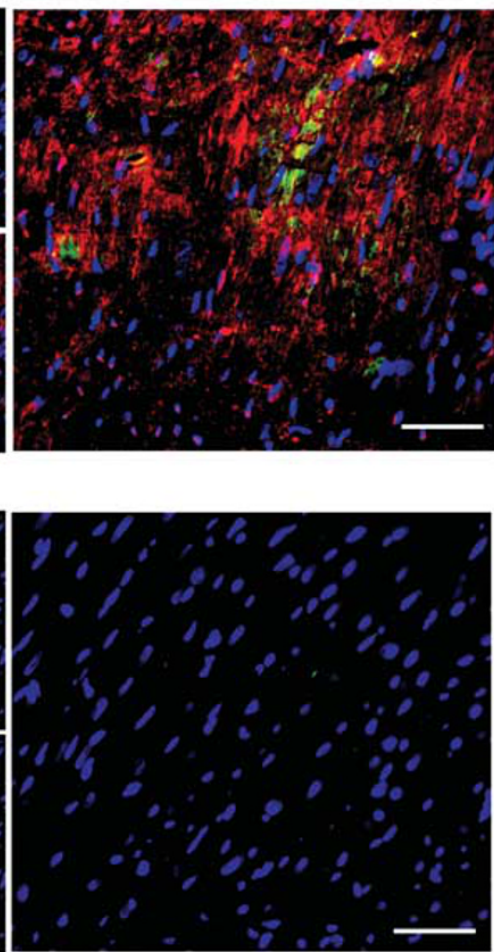

4-1BBL

4-1BB b
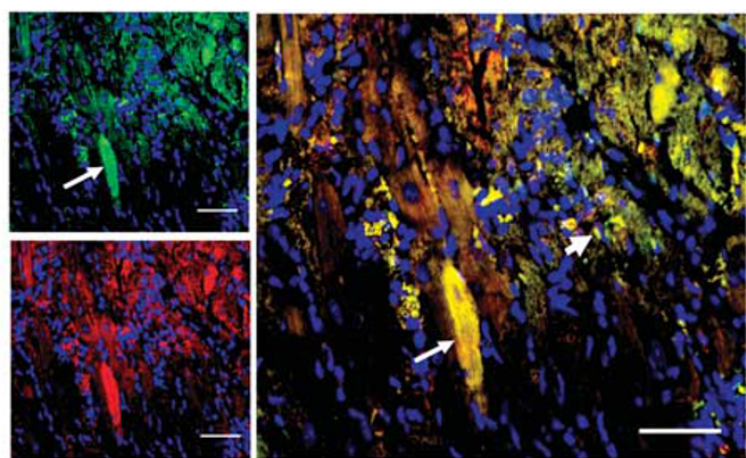

d
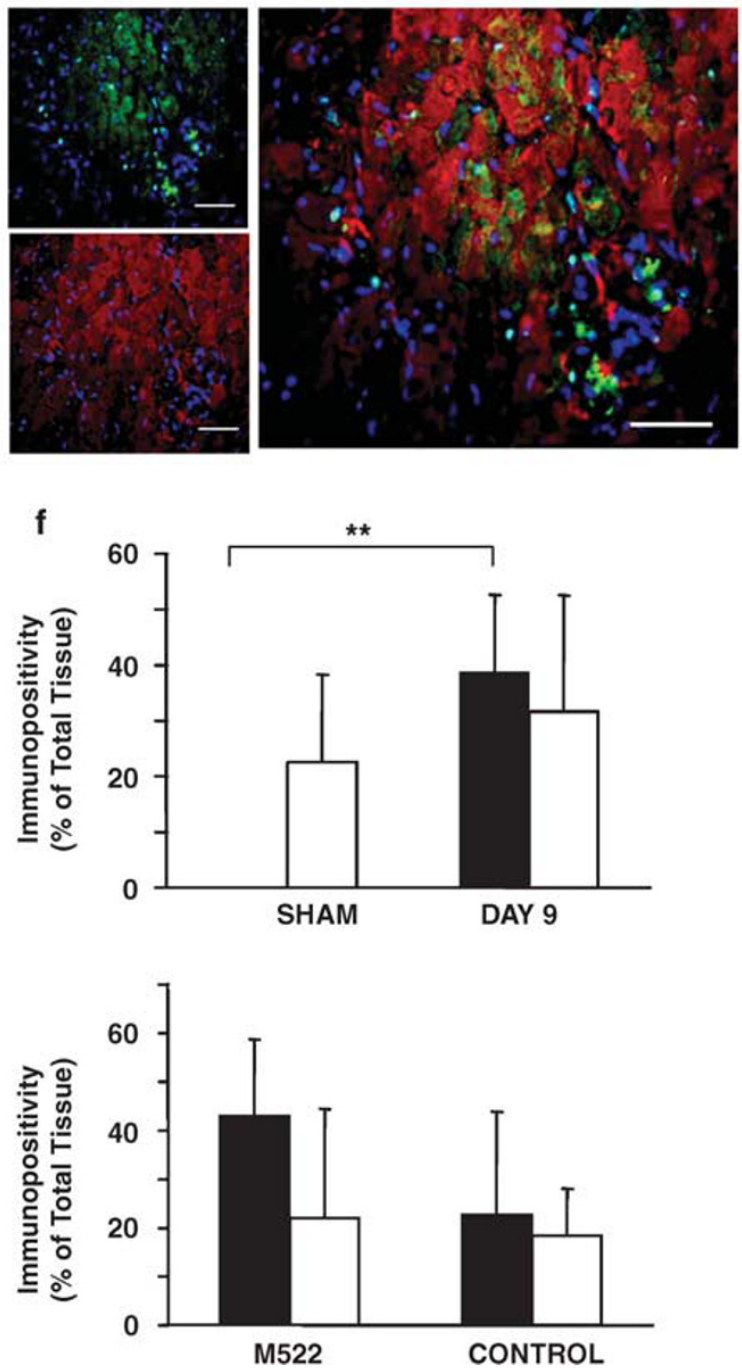

Figure 1 Expression of 4-1BB and 4-1BBL in mouse hearts. Representative myocardial sections from (a) sham ( $N=4)$, (b) CVB3-infected and untreated mouse at day $9(N=4)$, (c) infected and M522-treated $(N=9)$, and (d) infected and M525 control animals $(N=10)$ showing staining for 4-1BB (green, top small panels) and 4-1BBL (red, lower small panels). The large panels represent overlay of nuclear staining (blue) and colocalization of the two antigens (yellow). (e) Negative controls for 4-1BB and 4-1BBL using isotype-matched lgG. (f) Morphometric quantitation of 4-1BB and 4-1BBL protein expression. Scale bars $=50 \mu \mathrm{m}$. Data are mean \pm s.d. ${ }^{*} P<0.01$ sham vs infected.

at 10 weeks pi (Figure 1c and d) showed myocardial colocalization. At this time point, 4-1BBL was still strongly expressed in all tissue and no difference was found between the M522-treated (Figure 1c, red stain, lower small panel) and control hearts (Figure 1d, $P=0.7$ ). In contrast, there was faint, diffuse expression of 4-1BB (green stain, top small 
panels) and for the most part it was coexpressed with its ligand (orange, large panels). Both cardiomyocytes and small globular cells, possibly infiltrating cells expressed $4-1 \mathrm{BB}$, whereas mostly endogenous cells expressed $4-1 \mathrm{BBL}$. In M522-treated hearts, a trend towards increased 4-1BB immunopositivity as compared to the control group was detected although the difference did not reach statistical significance $(43 \pm 16$ vs $23 \pm 21 \%, p=0.1)$. Figure 1f shows the graphical representation of the densitometric analyses.

\section{Echocardiography}

Serial cardiac function measurements were taken by echocardiography. Figure 2a displays the histological cardiac images at various time points following infection (top four panels) and the mid-section and lower panels show the tracings for systolic and diastolic short axis ventricular measurements, respectively. At day 3 post-CVB3 infection, histological myocyte vacuolization was associated with a nonsignificant trend in reduced LV wall thickening but normal wall thickness, LVEF, and cardiac volumes in virusinfected mouse hearts as compared to shams (Figure 2b-e). By day $9 \mathrm{pi}$, the degree of wall thickening was reduced $(30 \pm 17$ vs $70 \pm 19 \%, P<0.01)$ and wall thickness was increased $(0.15 \pm 0.04$ vs $0.09 \pm 0.01 \mathrm{~cm}$ in diastole and $0.19 \pm 0.04$ vs $0.15 \pm 0.02 \mathrm{~cm}$ in systole, both $P<0.05)$ in CVB3-infected myocardium as compared to sham hearts, suggestive of wall edema and inflammation. Due to the increased wall thickness in the infected hearts, end-diastolic volume (EDV) was reduced at day 9 pi in myocarditic hearts as compared to sham $(0.013 \pm 0.003$ vs $0.024 \pm 0.003 \mathrm{ml}$, $P<0.002)$, whereas a decrease in end-systolic volume (ESV) was also observed in CVB3-infected hearts but did not reach statistical significance $(0.004 \pm 0.002$ vs $0.007 \pm 0.001$, $P=0.07)$. On day $30 \mathrm{pi}$, wall contractility remained depressed $(33 \pm 15$ vs $70 \pm 19 \%, P<0.05)$, left ventricular posterior wall (LVPW) thickness was still increased although this did not reach statistical significance $(0.12 \pm 0.01$ vs $0.09 \pm 0.01 \mathrm{~cm}$ in diastole $(P=0.08)$ and $0.16 \pm 0.01$ vs $0.15 \pm 0.02 \mathrm{~cm}$ in systole (NS)), the EF was reduced $(62 \pm 8$ vs $72 \pm 3 \%$, $P<0.005)$, and ESV was increased by $33 \%$ to $0.011 \pm$ $0.003 \mathrm{ml}(P<0.01)$ in myocarditic animals as compared to sham, indicative of intrinsic contractile deficits and systolic dysfunction.

To examine chronic cardiac dysfunction and to determine the role of the $4-1 \mathrm{BB}$ pathway, we conducted a therapeutic treatment study and extended our observations to 10 weeks pi. Mice were infected with CVB3 and randomly assigned into two groups. On day $15 \mathrm{pi}$, one group was administered a 4-1BBL neutralizing Ab (M522) and the other group was given a nonblocking Ab, M525 or control. Sham mice administered neutralizing or nonblocking antibodies experienced no functional changes as compared to sham mice with vehicle (data not shown). M522 therapy improved the rate of wall thickening, reduced wall thickness, and reduced EDV at 10 weeks pi as compared to the control group. Comparison of the rate of wall thickening at 10 weeks pi showed that the percentage change from baseline, defined as measurements taken from infected mice prior to infection, following M522 administration was $-9 \pm 13 \%$, whereas it was $-49 \pm 16 \%$ $(P \ll 0.0001)$ in control animals (Figure $3 \mathrm{a})$. This indicates that there was improved contractility in the M522-treated group, whereas the control animals still suffered severe contractile impairment.

M522 treatment also appeared to normalize LVPW thickness towards baseline values (Figure 3b). Diastolic LVPW thickness, expressed as percentage change from baseline, was significantly lower in the M522 group as compared to controls $(17 \pm 10$ vs $57 \pm 47 \%, P=0.03)$, indicating that during chronic myocarditis, the LVPW were still profoundly thickened in the untreated animals. However, systolic wall thickness was not statistically different between the M522-treated and control animals $(8 \pm 19$ vs $13 \pm 29 \%, P=0.66)$.

Figure $3 \mathrm{c}$ demonstrates that at 10 weeks pi as cardiac expansion and remodeling progressed, M522 administration significantly improved EDV as compared to control (16 14 vs $42 \pm 25 \%, P=0.03$ ), as determined by percentage change from baseline. No difference was observed in ESV between the M522 group and controls $(67 \pm 27 v s 85 \pm 49 \%, P=0.37)$. Systolic function, as measured by EF was reduced to $67 \pm 5 \%$ in both groups at 10 weeks pi as compared to $75 \pm 5 \%$ at baseline (data not shown).

\section{Histological Examination}

There was no significant difference in mortality rate between M522-treated and control mice (data not shown). As shown in Figure 4a, M522-treated animals exhibited significantly less myocardial injury than control animals ( 0 vs $1.3 \pm 1.5$, $P<0.05)$, as assessed by scoring of H\&E-stained cardiac sections. The M522 group showed little or no cardiac injury while controls experienced a great amount of damage, as evidenced by small diffuse lesions and scars (arrows) in their hearts. Some control animals experienced considerable histological injuries, such as multiple large scars and calcific lesions.

Cardiac sections were also subjected to picrosirius red staining for visualization of collagen amount and architecture, which was quantitated using Image-Pro Plus ${ }^{\circledR}$. Figure $4 \mathrm{~b}$ shows that control hearts stained with picrosirius red revealed a marked increase in collagen deposition as well as soft tissue distortion as compared to M522-treated myocardium $(4.9 \pm 2.2$ vs $3.2 \pm 0.6 \%, P<0.05)$ via assessment of collagen volume fraction. Increased perivascular, replacement, and reactive fibrosis were also observed in control hearts, whereas the M522 group demonstrated little fibrotic alterations. Such findings correlate with the histological grades, which indicate that control hearts had more damage and lesions. During this late phase, majority of the lesions were likely not active but had evolved into collagenous replacement and reactive fibrosis. 
a
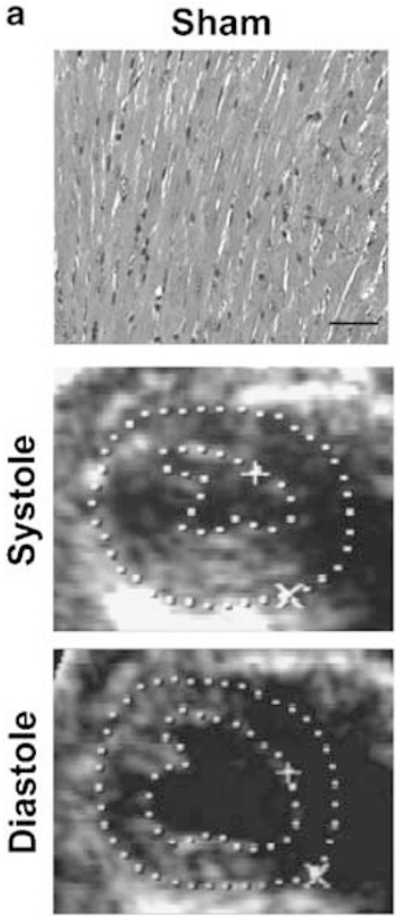

b

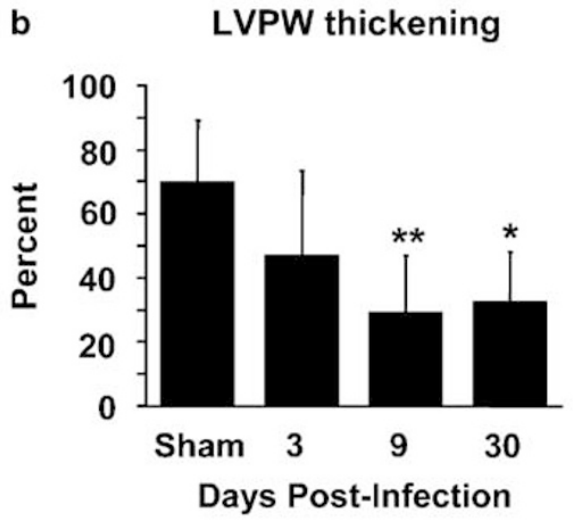

d

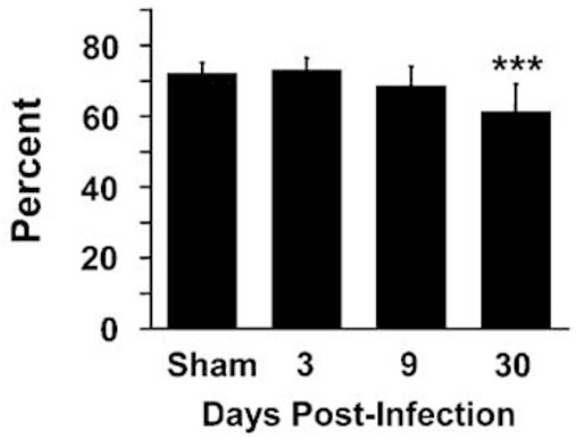

CVB3 Day 3
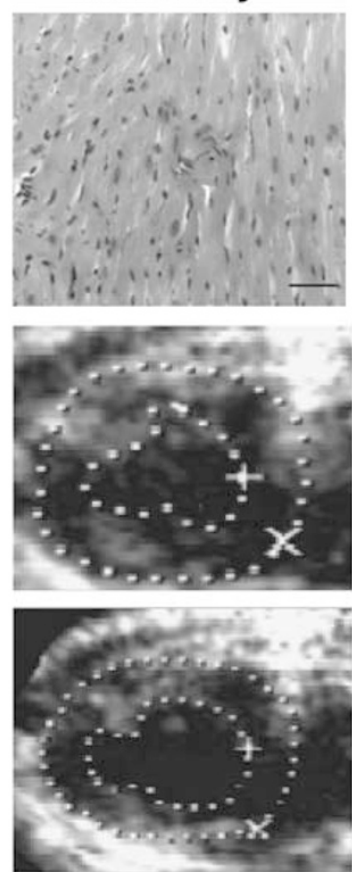

CVB3 Day 9
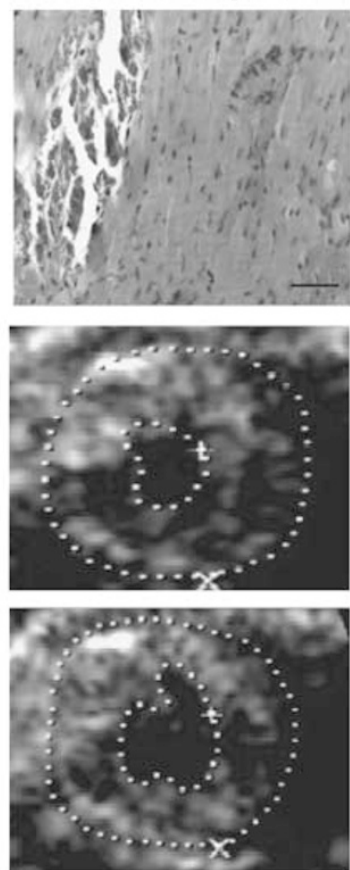

CVB3 Day 30
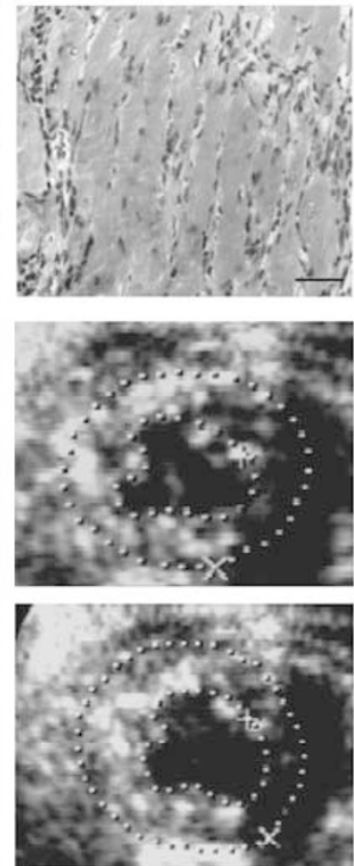

LVPW Thickness

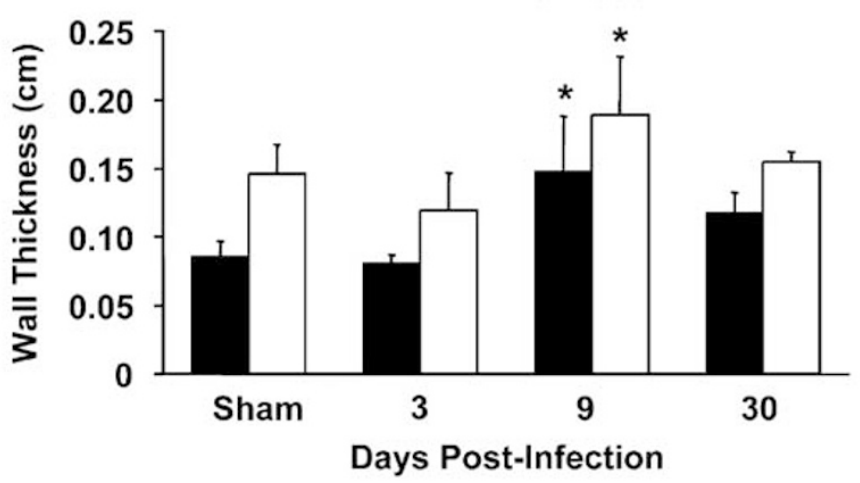

Diastolic

Systolic

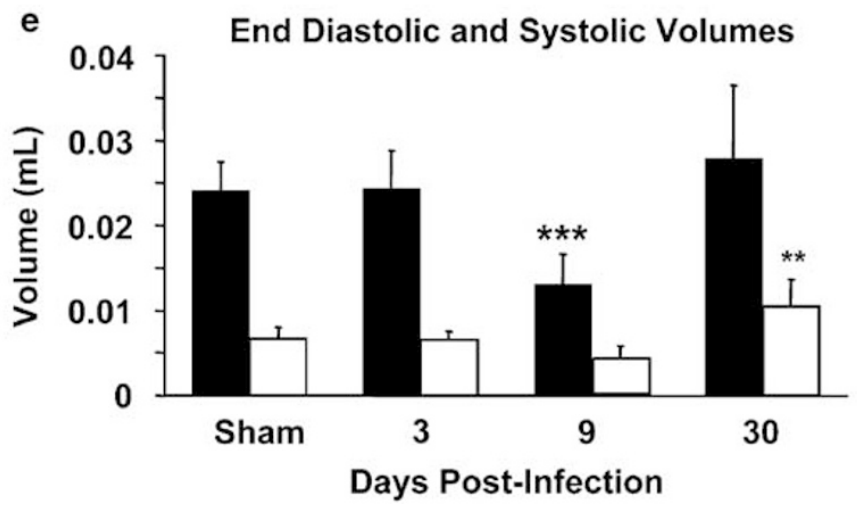

Figure 2 Depressed cardiac function in mice following CVB3 infection. (a) Representative H\&E sections of myocardium at 3, 9, and 30 days pi. Below are representative short axis ultrasound images taken at systole (middle panels) and diastole (lower panels) at the level of the papillary muscle, showing tracings of the myocardial wall and chamber. Echocardiography was performed on days 3, 9, and 30 pi and measurements for (b) LVPW thickening, (c) LVPW thickness, (d) LVEF, and (e) end-diastolic and systolic volumes were recorded. Scale bars denote $50 \mu \mathrm{m}$. Data are mean \pm s.d. ${ }^{\star} P<0.05,{ }^{\star} P<0.01$, $* * * P<0.005$, baseline vs infected, $N=4$ at each time point. 
a

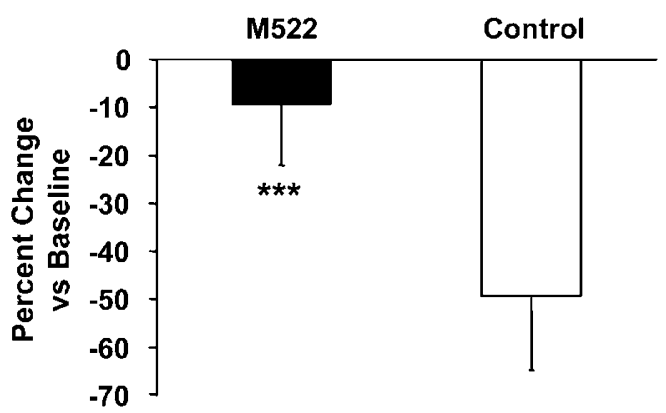

b LVPW Thickness in Diastole and Systole

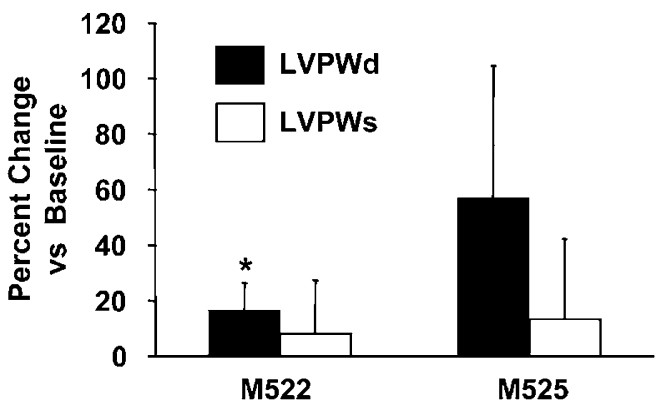

C End Diastolic and Systolic Volumes

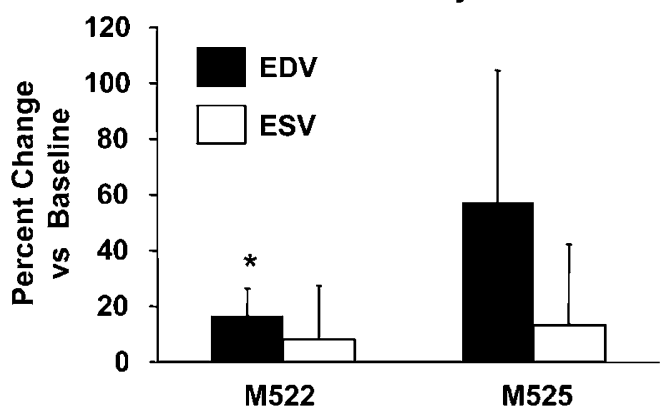

Figure 3 Effects of M522 treatment on cardiac function in mice. (a) Rate of LV wall thickening, (b) LVPW thickness, and (c) end ventricular volumes were measured at 10 weeks pi and we observed a significant difference in LV wall thickening rate between M522 and controls as well as moderate decreases in LVPW thickness and end-diastolic cardiac volume in M522treated mice. Data are mean \pm s.d., ${ }^{*} P<0.05,{ }^{* * * P}<0.005$. M522 $(N=9)$ and controls $(N=10)$.

\section{Protease Expression}

To determine if proteases were involved in the differential remodeling between M522-treated and control animal hearts, we used RT-PCR to compare the transcriptional levels of MMP-2, MMP-9, and MMP-12. These enzymes have previously been shown to be involved in acute myocarditis and may play a role in long-term remodeling. ${ }^{26}$ We found that neither expression of MMP-2 nor MMP-9 transcripts were significantly altered between the two groups, as shown in Figure 5. MMP-2 transcript was present abundantly in all samples, whereas MMP-9 was produced minimally in both groups. Interestingly, MMP-12 or metalloelastase was also expressed abundantly by both groups but the control group had increased expression of this transcript as compared to M522-treated animals, $P<0.05$. Densitometric quantitation of the PCR bands is presented in Figure $5 \mathrm{~b}$.

\section{Immunohistochemical Staining for Immune Cells}

To compare the degree of immune cell infiltration in M522treated and control animals after CVB3 infection, we stained for CD45, a pan-leukocyte marker, and CD3, a pan-T cell marker. At 10 weeks pi, active myocarditis had largely subsided but various stimuli, such as persistent viral infection or autoimmunity, may cause ongoing low-grade inflammation. Consistent with the histological results, we found that control animals exhibited increased immunopositivity for CD45 (Figure 6a, arrows), indicating more leukocyte infiltration than M522-treated animals $(8.5 \pm 4.1$ vs $5.9 \pm 1.3 \%$ of total cell fraction, $P=0.08$ ), although this differential CD45 infiltration did not reach statistical significance (Figure 6b). Of these immunopositive cells, the majority were $\mathrm{T}$ cells as shown by staining for $\mathrm{CD} 3$ (Figure 6), and the increase in this subset of lymphocytes in control hearts is statistically significant as compared to M522-treated animals $(4.3 \pm 3.8 \mathrm{vs}$ $1.3 \pm 0.9 \%, P<0.05)$. Owing to the scarcity of lesions and scars within the M522-treated animals, most of the leukocytes were diffuse and dispersed among cardiomyocytes. In control animals, the number and size of lesions were increased and we detected extensive immunopositivity for both CD45 and CD3 within and around these lesions (Figure 6a, arrows).

\section{DISCUSSION}

In this study, we treated CVB3-infected mice with neutralizing anti-4-1BBL or control nonblocking $\mathrm{Ab}$ for up to 10 weeks beginning from 2 weeks pi. As such, we studied the chronic phase of this disease in a clinically relevant model. We began treatment at day 15 to determine the role of the $4-1 \mathrm{BB}$ pathway and $\mathrm{T}$ cell regulation on cardiac function and this treatment regimen is clinically relevant as patients rarely present during a fulminant immune response. We show significant improvements in cardiac function after blocking 4-1BBL interaction with its receptor, as measured by maintenance of LVPW thickness, LV contractility, and EDV. We also observed less fibrosis, cardiac tissue injury, inflammation, and remodeling within the hearts treated with M522. Previous observations have shown that $4-1 \mathrm{BBL}$ is increased in cardiomyocytes after CVB3 infection in mice and in cases of human DCM. ${ }^{22,23}$ In our study, we further show that both 4-1BBL and 4-1BB were increased in cardiomyocytes after virus infection.

We studied the 4-1BB pathway in experimental myocarditis as it has previously been implicated in inflammation and apoptosis. The 4-1BB receptor is expressed on CD8 + $\mathrm{T}$ cells upon ligation with its ligand, which stimulates proliferation and activation of these cells, thus aiding in tumor and virus clearance. ${ }^{27,28}$ In vitro, stimulation of the $4-1 \mathrm{BB}$ 
a

M522

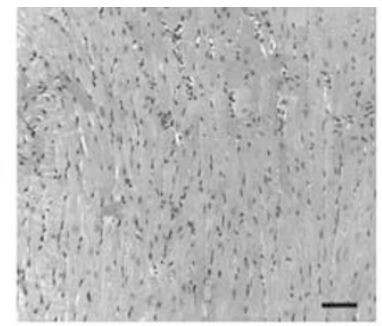

CONTROL

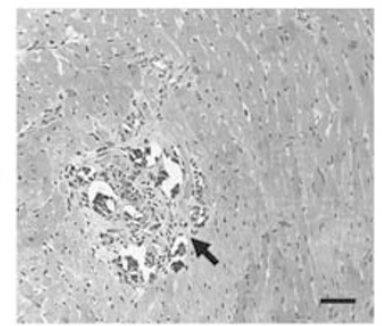

b

M522

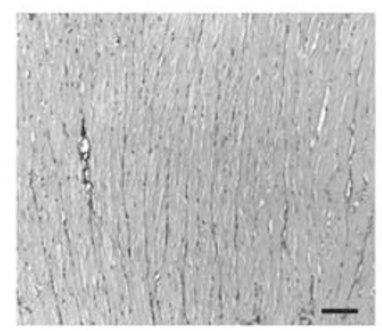

CONTROL

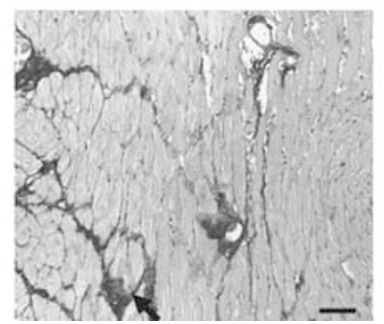

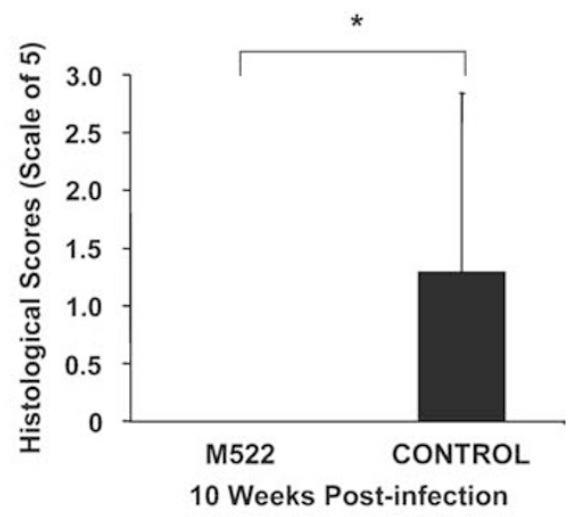

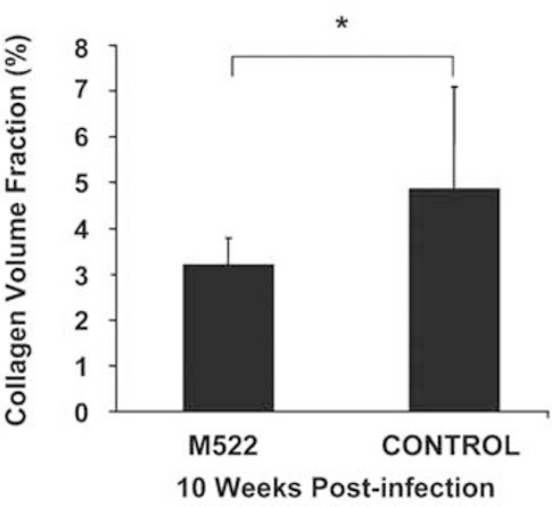

Figure 4 Improvement of pathological findings in chronic myocarditis after anti-4-1BBL neutralizing $A b$ treatment of mice following CVB3 infection. (a) Representative myocardial sections showed markedly decreased inflammation and tissue damage in M522treated hearts $(N=9)$ as compared to control hearts $(N=10)$. Semiquantitative histological grades for necrosis and tissue granulation as well as for inflammation and edema were significantly lower in M522-treated hearts as compared to the control group (0 vs $1.3 \pm 1.5$ ). Sham tissues exhibited no measurable pathological changes (data not shown). (b) Picrosirius staining for total collagen distribution demonstrated decreased collagen accumulation and scars or lesions (arrows) in the M522 group $(N=9)$ as compared to control hearts $(N=10)$. Quantitative assessment for collagen volume fraction as measured using the Image-Pro Plus ${ }^{\circledR}$ program was significantly lower in M522-treated hearts as compared to control $(3.2 \pm 0.6$ vs $4.9 \pm 2.2 \%)$. Sham tissues exhibited no measurable pathological changes (data not shown). Scale bars $=50 \mu \mathrm{m}$. Data are mean \pm s.d., $* P<0.05$, M522 vs control. receptor activates both $\mathrm{CD} 8+$ and $\mathrm{CD} 4+\mathrm{T}$ lymphocytes but in vivo, the response is skewed towards stimulation of CD $8+$ cells and abatement of CD $4+$ T cells. $^{29}$ This pathway has important roles in influenza, herpes, and HIV infections. Studies have shown that agonistic anti-4-1BB antibodies improve antiviral mechanisms, exhibited predominantly by increased proliferation of CD8 $+\mathrm{T}$ cells. The authors suggested that activation of the 4-1BB pathway upregulates INF$\gamma$ secretion, increases proliferation of CD8 + T cells, inhibits activation-induced cell death of these cells, and expands memory $\mathrm{T}$ cell population to protect against future infections. $^{28,30}$ However in our disease model, the immune response likely has both host protective and detrimental effects. During acute myocarditis, the immune response is crucial in clearing the virus and instigating the healing process. However, protracted inflammation is damaging to the myocardium and persistent virus infection can lead to immune-mediated attack on both infected and noninfected cardiomyocytes. $^{31}$ Autoimmunity may also play a role involving both $\mathrm{CD} 8+\mathrm{T}$ cells and auto-antibodies. ${ }^{31}$ Therefore, our study was designed to target the late chronic phase of the disease; by treating CVB3-infected mice with antagonist anti-4-1BBL Ab to block activation of this pathway, the detrimental effects of $\mathrm{T}$ cells were circumvented. We report here that immune cells, in particular $\mathrm{T}$ cells, were indeed decreased in anti-4-1BBL-treated animals. However, we did not investigate the proportions of $\mathrm{CD} 8+, \mathrm{CD} 4+$, and $\gamma \delta$ TCR cell subsets in this study and this knowledge can clarify the roles of each $\mathrm{T}$ cell subtype in this model. Inhibition of the $4-1 \mathrm{BB}$ pathway during the late stage of the disease may decrease the activity of the detrimental CD8 + cells while sustaining the survival of CD $4+\mathrm{T}$ cells, thus improving the disease.

The 4-1BB/4-1BBL pathway is multifunctional. The 4-1BB pathway induces apoptosis in several cell types but the mechanisms are unclear. $^{12,19,20}$ Previous observations (unpublished data) have shown that $4-1 \mathrm{BB}$ receptor can be induced on cardiomyocytes under ischemic and cytotoxic conditions. Inhibition of activation of this pathway by using neutralizing anti-4-1BBL Ab improved disease after MI 
a

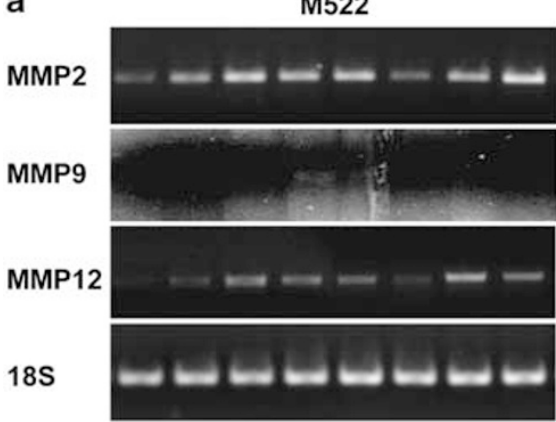

b

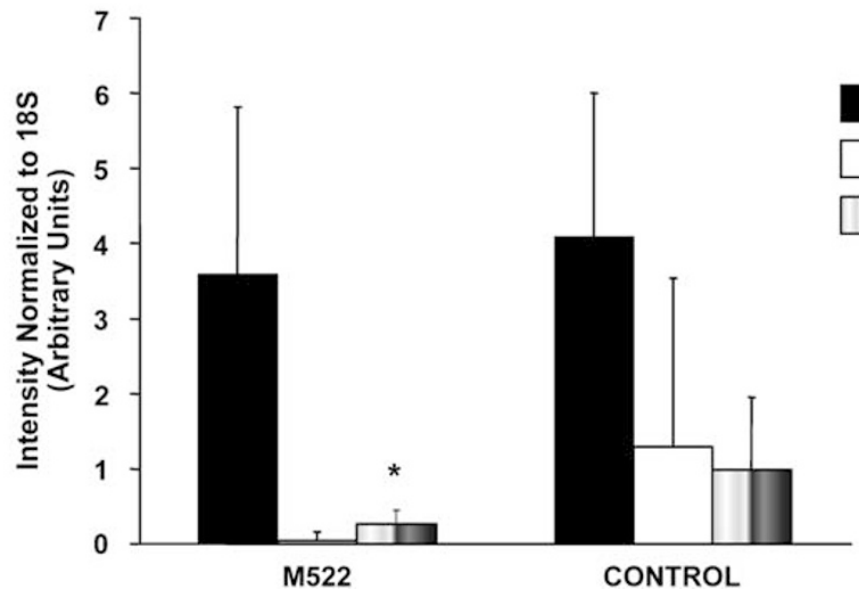

CONTROL

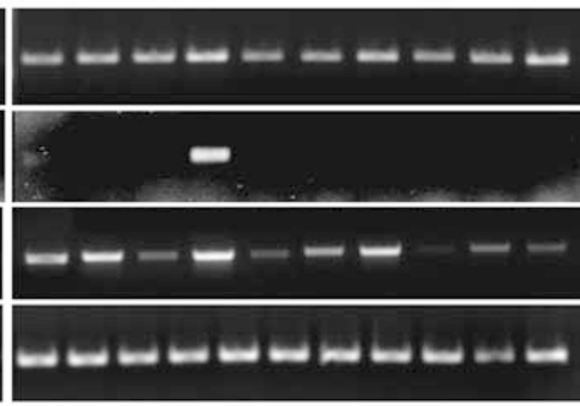

MMP2

MMP9

MMP12

Figure 5 Effects of 4-1BB inhibition on MMP-2, MMP-9, and MMP-12 expression. (a) Representative images showing semiquantitative RT-PCR for MMP-2, MMP-9, and MMP-12 transcription. Strong expression of MMP-2 and MMP-12, but minimal expression of MMP-9 was observed. (b) Densitometric quantitation of the PCR bands showed that while the gelatinases expression did not differ between the two groups, MMP-12 was significantly lower in the M522-treated animals. Data are mean \pm s.d., ${ }^{\star} P<0.05, \mathrm{M} 522(N=9)$ vs control $(N=10)$.

and doxorubicin-induced cardiomyopathy, possibly by downregulation of cardiomyocyte apoptosis via inhibition of mitochondrial dysfunction. This pathway involves induction of proapoptotic Bcl-2 proteins or creation of transition pores in the mitochondria inner membrane, leading to leakage of cytochrome $c$ activation of downstream caspases. ${ }^{32-34}$ Our laboratory has previously shown that mitochondrial disruption is a major cause of apoptosis during coxsackievirus infection and the virus often manipulates the host cell's apoptotic pathways to maximize replication and dissemination. ${ }^{35,36}$ Therefore, we speculate that 4 -1BB may operate in a mitochondria-dependent apoptotic pathway. However, TUNEL staining and caspase 3 cleavage assays did not show any differences between treatment and control tissues (data not shown). Viral myocytolysis primarily occurs during acute myocarditis, therefore at week $10 \mathrm{pi}$, overt cell death may not have been detectable.

Our results show that inhibition of $4-1 \mathrm{BB}$ activation after CVB3 infection contributed to positive cardiac remodeling. Picrosirius red staining demonstrated a reduction in lesions and scars within M522-treated mouse hearts. To further elucidate the mechanism for this phenomenon, we looked at the expression of MMPs. Our laboratory has previously shown that the gelatinases, MMP-2 and MMP-9, as well as the metalloelastase MMP-12 were increased during acute myocarditis and remained upregulated at 30 days pi. $^{26}$ We hypothesized that these proteases play a role in regulating the immune response by modulating the activity and expression of cytokines, and also in matrix remodeling. In this study, we found that MMP-2 and MMP-12 remained increased at 10 weeks pi in both groups while MMP-9, which we previously found to be predominantly secreted by immune cells, had returned to basal levels. However, metalloelastase was expressed substantially higher in the control animals than the M522-treated group, suggesting that this enzyme may play a major role in negative matrix remodeling and disease severity. This correlated to an increase in both CD45 + and $\mathrm{CD} 3+$ cells in control hearts. Even though immune cells are not the predominant source of MMP-12 in myocarditis, they produce many cytokines and other modulators of MMPs which induce resident cardiac cells to express MMPs. ${ }^{37}$ Therefore, increased inflammation may result in upregulation of cytokines to stimulate the expression of MMP-12. Note that MMP-2 was not affected by this phenomenon, indicating that this enzyme may not be as tightly regulated by the immune response as metalloelastase.

In conclusion, we found that neutralizing anti-4-1BBL $\mathrm{Ab}$ may be a novel therapeutic agent to prevent the chronic 
a
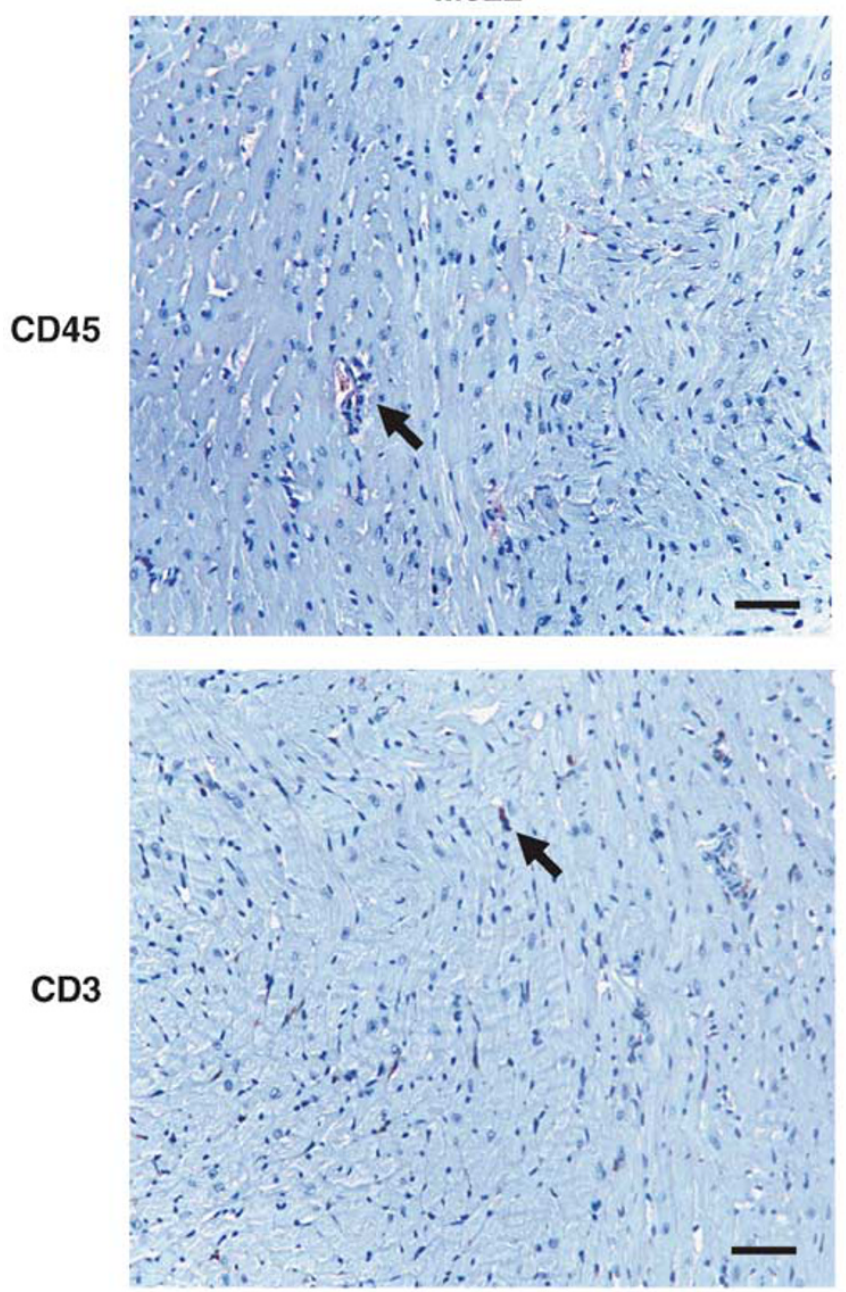

b

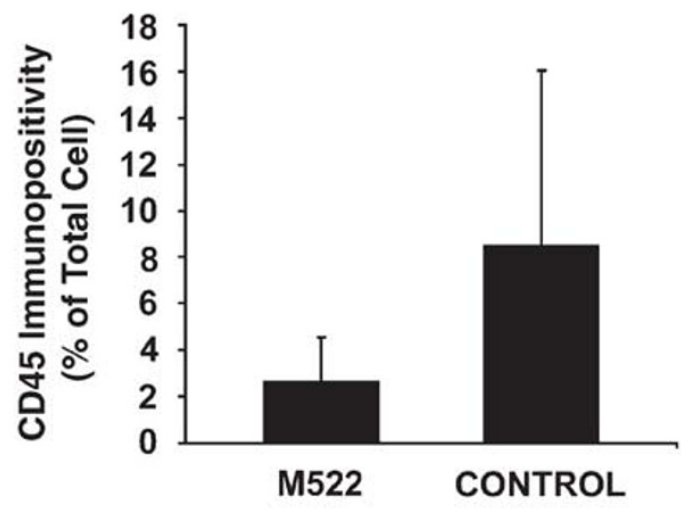

10 Weeks Post-infection
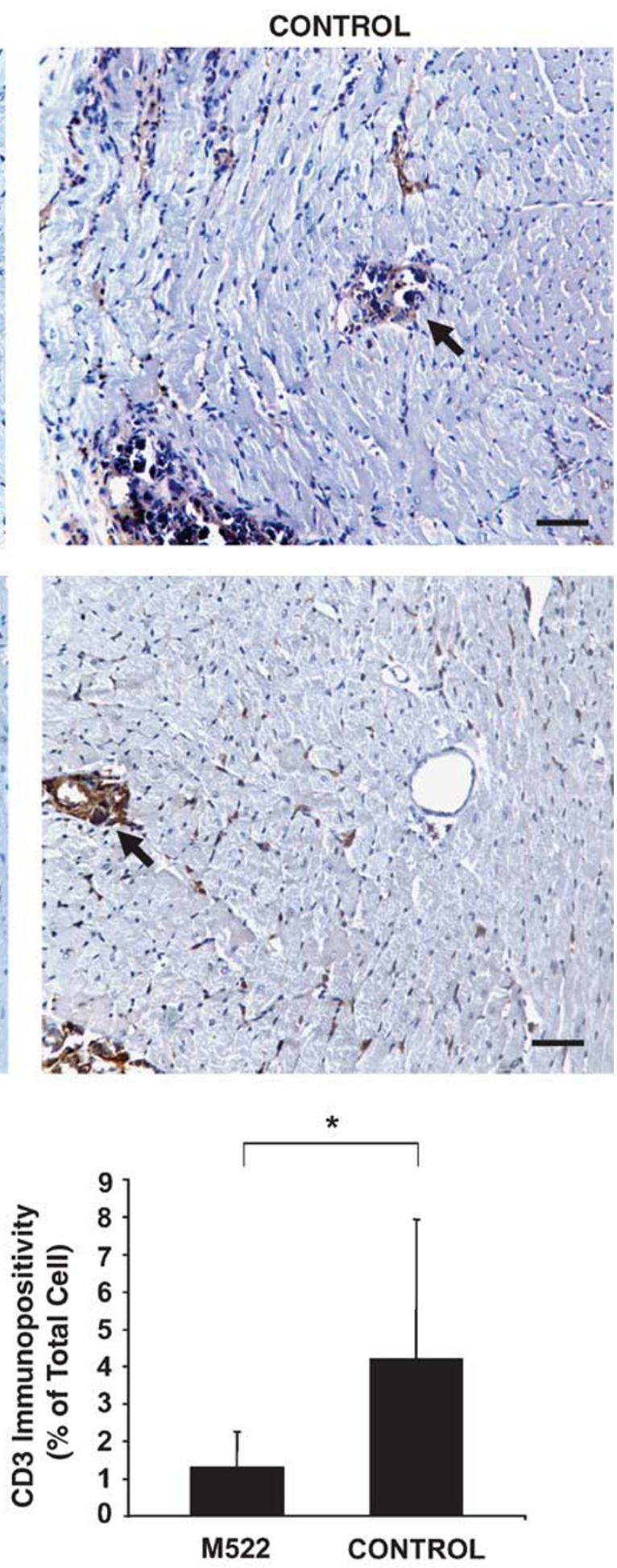

10 Weeks Post-infection

Figure 6 Inflammatory cell infiltration in M522-treated and control mouse hearts. (a) Representative myocardial sections showed markedly decreased inflammation as assessed by immunostaining for CD45 and CD3 in the M522-treated group as compared to control. In control hearts, immune cells, stained in brown, can be detected within lesions as well as diffusely among cardiomyocytes (arrows). (b) Quantitation of the immunoreactivity for CD45 and CD3 staining showed fewer immune infiltrates in M522-treated hearts as compared to control. Scale bars $=50 \mu \mathrm{m}$. Data are mean $\pm \mathrm{s} . \mathrm{d}$. ${ }^{*}<0.05, \mathrm{M} 522(N=9) v s$ control $(N=10)$. 
cardiac sequelae after CVB3-induced myocarditis. Most importantly, we have demonstrated that administration of a neutralizing $\mathrm{Ab}$ after the acute phase of infection had beneficial effects on chronic cardiac function. Modulation of the 4-1BB pathway may be a therapeutic target for human myocarditis-induced heart failure.

\section{ACKNOWLEDGEMENTS}

We thank Dr Jingchun Zhang, Ms Zongshu Luo, and Dr Ji Yuan for their technical support. This work was supported by research grants and fellowships from the Canadian Institutes of Health Research, Heart and Stroke Foundation of Canada, Heart and Stroke Foundation of British Columbia and Yukon, and Michael Smith Foundation for Health Research.

1. Grist NR, Reid D. Organisms in myocarditis/endocarditis viruses. J Infect 1997;34:155.

2. McManus BM, Chow LH, Wilson JE, et al. Direct myocardial injury by enterovirus: a central role in the evolution of murine myocarditis. Clin Immunol Immunopathol 1993;68:159-169.

3. Huber SA, Job LP. Cellular immune mechanisms in coxsackievirus group B, type 3 induced myocarditis in Balb/C mice. Adv Exp Med Biol 1983;161:491-508.

4. Kawai C. From myocarditis to cardiomyopathy: mechanisms of inflammation and cell death: learning from the past for the future. Circulation 1999;99:1091-1100.

5. Chow LH, Beisel KW, McManus BM. Enteroviral infection of mice with severe combined immunodeficiency. Evidence for direct viral pathogenesis of myocardial injury. Lab Invest 1992;66:24-31.

6. Kishimoto C, Abelmann WH. In vivo significance of T cells in the development of coxsackievirus B3 myocarditis in mice. Immature but antigen-specific T cells aggravate cardiac injury. Circ Res 1990;67: 589-598.

7. Henke A, Huber S, Stelzner A, et al. The role of CD8+ T lymphocytes in coxsackievirus B3-induced myocarditis. J Virol 1995;69:6720-6728.

8. Opavsky MA, Penninger J, Aitken K, et al. Susceptibility to myocarditis is dependent on the response of alphabeta $T$ lymphocytes to coxsackieviral infection. Circ Res 1999;85:551-558.

9. Watts TH. TNF/TNFR family members in costimulation of $\mathrm{T}$ cell responses. Annu Rev Immunol 2005;23:23-68.

10. Kim JO, Kim HW, Baek KM, et al. NF-kappaB and AP-1 regulate activation-dependent CD137 (4-1BB) expression in T cells. FEBS Lett 2003;541:163-170.

11. Pollok KE, Kim YJ, Hurtado J, et al. 4-1BB T-cell antigen binds to mature $B$ cells and macrophages, and costimulates anti-mu-primed splenic B cells. Eur J Immunol 1994:24:367-374.

12. Kienzle G, von Kempis J. CD137 (ILA/4-1BB), expressed by primary human monocytes, induces monocyte activation and apoptosis of $B$ lymphocytes. Int Immunol 2000;12:73-82.

13. Futagawa $\mathrm{T}$, Akiba $\mathrm{H}$, Kodama $\mathrm{T}$, et al. Expression and function of 4-1BB and 4-1BB ligand on murine dendritic cells. Int Immunol 2002:14:275-286.

14. Langstein J, Michel J, Fritsche J, et al. CD137 (ILA/4-1BB), a member of the TNF receptor family, induces monocyte activation via bidirectional signaling. J Immunol 1998;160:2488-2494.

15. Kim YJ, Mantel PL, June $\mathrm{CH}$, et al. 4-1BB costimulation promotes human T cell adhesion to fibronectin. Cell Immunol 1999;192:13-23.

16. Myers LM, Vella AT. Interfacing T-cell effector and regulatory function through CD137 (4-1BB) co-stimulation. Trends Immunol 2005;26: 440-446.

17. Kim J, Choi WS, La S, et al. Stimulation with 4-1BB (CD137) inhibits chronic graft-versus-host disease by inducing activation-induced cell death of donor CD4+ T cells. Blood 2005;105:2206-2213.

18. Kwon B, Lee HW, Kwon BS. New insights into the role of 4-1BB in immune responses: beyond CD8+ T cells. Trends Immunol 2002;23:378-380.
19. Heinisch IV, Daigle I, Knopfli B, et al. CD137 activation abrogates granulocyte-macrophage colony-stimulating factor-mediated anti-apoptosis in neutrophils. Eur J Immunol 2000;30:3441-3446.

20. Michel J, Pauly S, Langstein J, et al. CD137-induced apoptosis is independent of CD95. Immunology 1999;98:42-46.

21. Seko $\mathrm{Y}$, Takahashi N, Oshima $\mathrm{H}$, et al. Expression of tumour necrosis factor (TNF) receptor/ligand superfamily co-stimulatory molecules CD40, CD30L, CD27L, and OX40L in murine hearts with chronic ongoing myocarditis caused by coxsackie virus B3. J Pathol 1999;188:423-430.

22. Seko $\mathrm{Y}$, Takahashi $\mathrm{N}$, Oshima $\mathrm{H}$, et al. Expression of tumour necrosis factor (TNF) ligand superfamily co-stimulatory molecules CD30L, CD27L, OX40L, and 4-1BBL in murine hearts with acute myocarditis caused by Coxsackievirus B3. J Pathol 2001;195:593-603.

23. Seko $Y$, Ishiyama $S$, Nishikawa $T$, et al. Expression of tumor necrosis factor ligand superfamily costimulatory molecules CD27L, CD30L, OX40L and 4-1BBL in the heart of patients with acute myocarditis and dilated cardiomyopathy. Cardiovasc Pathol 2002;11:166-170.

24. Yanagawa B, Spiller OB, Proctor DG, et al. Soluble recombinant coxsackievirus and adenovirus receptor abrogates coxsackievirus b3-mediated pancreatitis and myocarditis in mice. J Infect Dis 2004;189:1431-1439.

25. Lang RM, Bierig M, Devereux RB, et al. Recommendations for chamber quantification: a report from the American Society of Echocardiography's Guidelines and Standards Committee and the Chamber Quantification Writing Group, developed in conjunction with the European Association of Echocardiography, a branch of the European Society of Cardiology. J Am Soc Echocardiogr 2005; 18:1440-1463.

26. Cheung $\mathrm{C}$, Luo $\mathrm{H}$, Yanagawa B, et al. Matrix metalloproteinases and tissue inhibitors of metalloproteinases in coxsackievirus-induced myocarditis. Cardiovasc Pathol 2006;15:63-74.

27. Zhang $\mathrm{H}$, Knutson KL, Hellstrom KE, et al. Antitumor efficacy of CD137 ligation is maximized by the use of a CD137 single-chain Fv-expressing whole-cell tumor vaccine compared with CD137-specific monoclonal antibody infusion. Mol Cancer Ther 2006:5:149-155.

28. Kim YH, Seo SK, Choi BK, et al. 4-1BB costimulation enhances HSV1-specific CD8+ T cell responses by the induction of CD11c+CD8+ T cells. Cell Immunol 2005;238:76-86.

29. Vinay DS, Cha K, Kwon BS. Dual immunoregulatory pathways of 4-1BB signaling. J Mol Med 2006;84:726-736.

30. DeBenedette MA, Wen T, Bachmann MF, et al. Analysis of 4-1BB ligand (4-1BBL)-deficient mice and of mice lacking both 4-1BBL and CD28 reveals a role for 4-1BBL in skin allograft rejection and in the cytotoxic T cell response to influenza virus. J Immunol 1999;163: 4833-4841.

31. Huber SA, Born W, O'Brien R. Dual functions of murine gammadelta cells in inflammation and autoimmunity in coxsackievirus B3-induced myocarditis: role of Vgamma1+ and Vgamma4+ cells. Microbes Infect 2005;7:537-543.

32. Kroemer G, Martin SJ. Caspase-independent cell death. Nat Med 2005; 11:725-730.

33. Green DR, Kroemer G. The pathophysiology of mitochondrial cell death. Science 2004;305:626-629.

34. Granville DJ, Carthy CM, Yang D, et al. Interaction of viral proteins with host cell death machinery. Cell Death Differ 1998;5:653-659.

35. Carthy $\mathrm{CM}$, Yanagawa $\mathrm{B}$, Luo $\mathrm{H}$, et al. $\mathrm{BCl}-2$ and $\mathrm{BCl}-\mathrm{xL}$ overexpression inhibits cytochrome $c$ release, activation of multiple caspases, and virus release following coxsackievirus B3 infection. Virology 2003;313:147-157.

36. Zhang HM, Yanagawa B, Cheung P, et al. Nip21 gene expression reduces coxsackievirus B3 replication by promoting apoptotic cell death via a mitochondria-dependent pathway. Circ Res 2002;90: 1251-1258.

37. Shimizu K, Shichiri M, Libby $\mathrm{P}$, et al. Th2-predominant inflammation and blockade of IFN-gamma signaling induce aneurysms in allografted aortas. J Clin Invest 2004;114:300-308. 